The Society should set an example by supporting the campaign for a 2050 decarbonisation target, argues Martin Lack

was very disappointed when the Advertising Standards Agency (ASA) banned an ExxonMobil advert for investment in algal biofuels some years ago. Where land is cheap and sunshine abundant (such as deserts), researchers have already shown that algae can be genetically modified to produce twice as much lipid as is produced normally-lipid that can be made into fuel. However, the ASA apparently objected to ExxonMobil's assertion that algal biofuels could reduce carbon emissions (i.e. rather than climate change). Sadly, the ASA's decision betrays a total failure to appreciate that, unlike fossil fuels, burning algal biofuels will not contribute to global warming; thanks to the short-term carbon cycle and the fact that this will not involve adding lithospheric carbon to the atmosphere.

\section{Significant alterations}

One of the most persistent fallacies repeated by climate science deniers is that " $\mathrm{CO}_{2}$ is plant food". Certainly, atmospheric $\mathrm{CO}_{2}$ concentrations were much higher in the Carboniferous era (the clue is in the name) in which plants got very big! However, given that human civilisation is primarily the result of the stable climate and sea levels since the last ice age, there should be very little doubt that it will be bad news for humanity if Earth's climate is now altered significantly; especially if, as now, that change is happening faster than at any time in Earth's history.

Thankfully, the Geological Society does not dispute any of the above. Indeed, in its position statement on climate change, the Society has cautioned that the Earth may take 100,000 years to reverse the changes that will be caused if humans burn all Earth's fossil fuels three million times faster than it can recycle them.

As we have now been warned by the Intergovernmental Panel on Climate Change-a panel of experts assembled in the 1980s before the fossil fuel industry decided to copy the tactics of the tobacco industry and spend huge amounts of money confusing the public, so as to delay the sensible regulation of their products-if humanity wants to prevent climate change from leading to the sixth mass extinction in Earth's history, we have less than 12 years to radically change the way we generate power.

Given that the rate of glacier melting has increased six-fold in the last 40 years, if we do nothing, they could be melting 36 times faster than they are today by the end of the century. We are already witnessing changes in our climate. This is strong empirical evidence that, unless we take action to prevent them, the changes that occur will-as Sir David Attenborough has warned-lead to the extinction of the majority of species of life on Earth.

\section{Campaign}

That being the case, I suggest that it is now time for the Society to go one step further and-as have esteemed bodies such as the Chartered Institute of Water and

Environmental Management, the Institute of Civil Engineers, and the Institute of Environmental Management and Assessment-support the campaign by The Climate Coalition (formerly the Stop Climate Chaos Coalition) to persuade our politicians to legislate for a 2050 Decarbonisation Target. In other words, the aim would be for the UK to achieve net-zero emissions by 2050 (that is, allowing for the possibility of carbon sequestration to be greater than fossiliferous emissions.

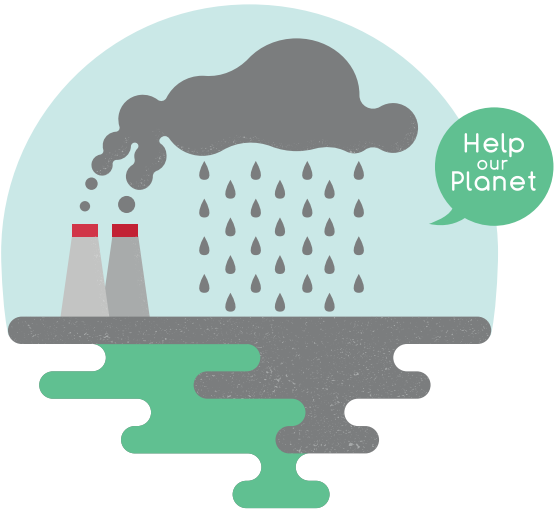

SOAPBOX CALLING!

Soapbox is open to contributions from all Fellows. You can always write a letter to the Editor, of course, but perhaps you feel you need more space?

If you can write it entertainingly in 500 words, the Editor would like to hear from you. Email your piece, and a self-portrait, to

amy.whitchurch@geolsoc.org.uk. Copy can only be accepted electronically. No diagrams, tables or other illustrations please.

Pictures should be of print quality - please take photographs on the largest setting on your camera, with a plain background.

Precedence will always be given to more topical contributions. Any one contributor may not appear more often than once per volume (once every 12 months).

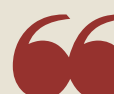
HUMANITY HAS LESS THAN 12 YEARS TO RADICALLY CHANGE THE WAY WE GENERATE POWER

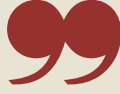

MARTIN LACK 